\title{
Promote Combinational Researches, Training, and Applied Scientific Technology in Universities and Institutes in Vietnam
}

\author{
Thi Dung Nguyena, Hong Phuc Nguyen ${ }^{b}$
}

\begin{abstract}
To promote the combination of research, training, and scientific technology application is the main policy of the Vietnam Communist Party and State of their management to their meeting of the needs toward their radical and comprehensive renovation with educational and training processes. There are some solutions such as: To develop a national project on combination of research and scientific technology application in social science in Vietnam was administered, to develop a set of criteria to ensure effectiveness of combination of research and training which will be based on the needs of society was assessed, to increase self-control of research institutes and universities of social science sector in combination of research and scientific technology application was examined, to be continued of the renovation management mechanism was managed, the cost norm and means of providing finance research and scientific technology application in social science were founded. The comprehensive legal framework and criteria of combination of research and scientific technology application as a basic for evaluating activities of research and scientific technology application in social science were used. Suggestions that this study was to apply scientific technology in transferring national university and investigation of the key universities into universities' researches were provided.
\end{abstract}

Keywords

Scientific, train, institute, university, social science

The international background of the first twenty-first century is the development of revolution of the information science, enhancing the knowledge-based economy's development. This background is influenced strongly by content and method of education for both normal university and post-university. However, many opportunities and challenges for education and development of the social science were introduced. The educating social sciences that ought to change in the globalization of the whole persons and throughout in the nation were interested.

Nowadays, the labors' skills in the regional economies ought to be needed to develop their higher quality on their work, consequently. Many researches in Asian nations reported on the the labors' skills in the regional economies in each country which had been changed and showed on their high qualiy of their skills for developing economical sectors with affecting

aUniversity of Labour and Social Affairs, Hanoi city, Vietnam bMilitary Medical Chamber, National Defense Academy, Hanoi city, Vietnam

\section{Correspondent Author:}

Thi Dung Nguyen, Department of Inspect, University of Labour and Social Affairs, 43 Tran Duy Hung street, Trung Hòa ward, Cau Giay district, Hanoi city, Vietnam 
situation in their region from the specialization of local traditional products, such as: rice, cereal, oil, etc. were provided. Focusing on a specialized region where it has improved the labors' skills to support the industrial products, namely, in the electronic products that there are a lot of developments of the labors' skills to their professions and continuing improvements. Suggestions are that the sectors of labor are also transformed strongly and promptly. Labors are also transformed from agricultural works to industrial works (both in producing and service themselves); the producing technology that has been based on the natural source ought to have working skills for the producing technology to promote on the whole labors. Morever, the regional economics must improve labors' skills in the transformation of their knowledge managements similar as in Japan, Korea, or Singapore whereas the religional labors' skills have higher developing quality than in South East Asian countries, such as: Vietnam, Thailand, Philippines, and Indonesia (Vietnam Social Science Institute 2011).

The combination of research, training, and scientific technology application of the Vietnam is currently conducted in formative manner and ineffective, particularly in social science sector. Meanwhile, demand for integrating research and training in social science block has been very urgent. To overcome this situation, the measures able to take, promote, and strengthen on the combination of research and scientific technology application were included.

It is subject to contribute to providing the scientific foundation for the implementation of the policy and guidelines of the Vietnam Communist Party and State for social science education. It is subject to assess the whole picture on the status of the combinational training researches on applied scientific technology of social science in universities and institutes; and propose yet the lessons of practical experience of some developing countries, and regional transformation.

\section{MATERIALS AND METHODS}

The authors have applied interdisciplinary approach (pedagogy, economics, sociology, etc.) as an effective manner; helping the reader have a multifaceted look on the situation and promote some measuring of the combinational and training researches on applied scientific technology of social science in universities and institutes in Vietnam.

The authors have applied the methods such as: statistical methods, survey methods, methods of analysis-synthesis, quantitative methods, qualitative methods, information processing method, research methods of text document, expert methods, etc. The modern research methods have been used thoroughly and matching themes should have achieved the targeted set of topic.

The paper uses methods of analysis and synthesis to handle the information related to the subject. Research methods which are mainly to reflect the current status of scientific research capacity and technology in the field of social science in universities and institutes in Vietnam are methods of analysis-synthesis, quantitative research methods, and qualitative methods.

\section{RESULTS}

As a result, the need of educating labors is increasing their development of their training skills day by day. For example, in the simple industry, the regional labors should be understood and trained of their industrial producing skills for acting and controling machines that have been complex skills on the program composition and designing technologies perfectly. The need ought to be increased for supplying of their skills of the whole labors who have never been satisfied timely in previous time, it caused the inadequation of labors' skills indicating that they 
had lower quality skills in Asia over the past decade.

The inadequate labors' skills have revealed that an effect on this research result for absorbing investment of the foreign capital resources is influencing the result of growth and development of each national economy. The combinations of this study between the practicing through an association of learning knowledge and the needs of labors' skills of their works were found (Eghbal 2008).

The business environment has also changed quickly thanks to the boom in technology. Exactly, the advance technology is applied into the business and production highly appreciated by the enterprises. The standardized daily life for people should be improved for their living styles in satisfaction and developing sustainably all times with the enterprising innovations to reduce the expense, and apply science and technology to production and sale of the consumers' demands to their products, fortunately.

The enterprising needs ought to be trained by trainer labors and labors who are able to do well in work efficiently and may not be retrained of their high quality skills, immediately. These labors will save the enterprises from expense of training and re-training, reducing the cost-price and increasing the products' competitiveness in the market. Generally, balancing competition of the demand and supply of labor skills, the training of human resource has to be updated for all times to satisfy the real life of their advances on science and technology. Asking for balance of the training units has to lead to connection with enterprising and researching sectors deeply.

The trend of curriculum reform in schools steadily narrows the gap between training and practice, and bridges the gap between researches and users of research results.

In Vietnam, the combinations between researching and training were investigated with formality on researches and effects in the branch of social science, especially. The structural organization of institutes and universities of the branch of social science was dissatisfied with three missions, namely: training skills, research on science, and applied sciences of the results and products.

Basically, the specialized departments that belong to the universities (faculty, researching center) of the implementations to the target in each field of research have never gone on searching needs to management and checked status of the independent subject in implementing the science researching topic, consulting the policies, and criterial science. The patterns of combining and finacial mechanism had never been searched and trained for previous research study to develop currently status in the institutes and universities for sustainablity. There is not any pattern of combining and financial mechanism which is suitable with the researching and training at the institutes and universities under the social science branch. The administrative and financial procedures for this combination are still bureaucratic, obstructed for the researching of interdisciplinary branches and multi-branches of the social science and natural science. Moreover, the reality showed that the result of university education in Vietnam is only teaching rather than researching and applying to the reality (T. D. Nguyen and T. T. Nguyen 2013).

\section{Associations Between the Urgent Solutions for} Promoting the Combination of the Researching and Training Scientific Technology and Application to Promote on the Branch of Social Science in Institutes and Universities in Vietnam

Selected a national project on the researching and training combinations of the social science in Vietnam at present. The educational reformation of the university and research in science required with the innovation is componential in thinking, evaluating, and ignoring the conservativeness, complacence of the leaders and memberships of universities and institutes belonging to the social science. The strategy and scheme are to develop social science for Vietnamese 
who have never been successful as they ought to be inadequate on human resource for supplying social science of their researching and training combinations. The national project is able to develop the social science for Vietnamese meanwhile as it might be self-controlled in their unities with researching and training the creative activities correctly (Vietnam Social Science Institute 2011; Vietnamese Government 2004; 2005a; 2005b; 2007).

Building the criteria to ensure the effectiveness of uniting the researching and training scientific technology application based on the specification of social needs. To ensure the effectiveness of uniting the researching and training, scientific technology applications are appreciated to be followed as:

(1) The research on science system of training targets as the uniting is going on management, successfully based on the real demand all of the campuses throughout the universities in Vietnam, respectively;

(2) Making regularly a survey method for evaluating the real needs and reacting capability of the training facilities was administered with the combinational research to manage educational training program of Vietnamese teachers for improving their teaching quality to indicate their satisfaction of their training requirements actually;

(3) Changing programs of contents and methods were trained for decreasing or increasing general theory of students' handling mindsets of passive way by the case study approach to their practical lessons. Teachers' presentations of their teaching style for enhancing students' discussions and their abilities to their self-studies were reduced onto organizing scientific research contests toward their major subjects that were associated. Combinations between students' assessments and their improving teamwork for presenting abilities were differentiated by enhancement of students' actual forms (Ministry of Education and Training 2007; Nguyen 2013);

(4) Focusing on the practicing facility assessments that are fastened on cooperation of universities and the social science institutes to arrange and develop students' acquainting scientific methods with this scientific research program for equipping and supporting their skills sustainability;

(5) Teamwork with students' partners and participants for encouraging the training units that are taken advantage of cooperation and scientific researches with institutional and enterprising researches with the collective practicing guides was used;

(6) Strengthening international cooperation in training and scientific research of students to exchange programs on their scholars and international experiences in foreign contents that are trained and practiced to their teachers who are instructing in the religion universities to exchange teaching styles on international techniques with the oversea people or foreigners. This situation reveals that the cooperative training as scientific research is to support Vietnamese teachers who should be going on the international teaching management styles with the foreign methods and programs;

(7) Strengthening the infrastructure and creating favorable conditions for scholars in collaboration with teachers and students who participate to seek in these research topics as combinational practicing theory.

Strengthening autonomy right for the research institutes and universities belonging to social science in combining research and training.

(1) Research institutes and universities belonging to social science should search and create conditions for developing relationships with local authorities or centers (which) that are required on training and scientific research;

(2) The scientifical and technological developing strategy to search on sectors is suitable with the capacity, advantage, and practical requirements of the region;

(3) The autonomy of the institute shows the objectives that it is identified research topics which 
ought to have actual needs from the awareness of the social problem. The researcher teams were improved and developed of their academia to attract young talent with their passions. The institutional activities should have the fund for supporting independent management of the state to arrangement for encouraging state researchers;

(4) In terms of the social science in universities, it shows their autonomy to their development of students' and teachers' skills, such as: The innovative programs are to allow and encourage methods, the scholarship program to encourage the spirit of students' learning is stepped up by seeking research. Students' talent is discovered by activities and initiations of their developing rudimentary thoughts into science by arrangement of their universities.

Continuing reformation of the management mechanism, norms, and modes of financial allocations in research activities and training social science sector. To improve the constant quality of scientific and training research in institutions and universities, it should be arranged for personnel participants to fix activities up with the national quality and inspectional system for graduating involvement and testing international quality system. The government's policy needs ought to support the funding priorities for building research activities in universities and institutes with regional and international qualification increasingly. This status has been established on necessary competitive methods of allocations and funds from the state's institutes and universities, in order to manage the practicing combinational research for applying and conducting the social science research, increasing investment efficiency for scientific activities is completed (Le 2007).

Completing the legal framework and using standardization to combine research and training social science to become fundamental system for evaluating research and training social science sector. To apply the transformation to national and key universities must promote the methods of universities' and institutes' researches in Vietnam, interestingly.

\section{CONCLUSIONS}

Nowadays, the global trend of globalization and international integration is happening on development and promotion throughout memberships of educators and researchers to their daily working strongly. In terms of the higher education systems in the developing countries, including Vietnam, they are deeply affected by the (new) modern educational philosophy - the philosophy of "learning society" and the knowledge economy is promoted.

To integrate into educational activities, national universities, key universities should have a suitable roadmap for transition to improve study in (studying) universities with three main functions, such as: training social science research, scientific method research, and satisfying social demands.

Requirements of coordinational social science researches in (between research) institutes and universities are for building research and training methods. Vietnamese social science should achieve a level sufficient to meet the requirements and co-operation of the international social science. Only by the total force and integration of scientific strengths and experiences of these subjects, could it be taken for developing social science in Vietnam.

Moreover, institutes and universities also have many same functions/tasks such as training, research, and international cooperation. This is also the basis for combination between institutes and universities in training and research. This integration is an objective, scientific, and real product to develop general social science in particular. The effective combinations between universities and institutes are necessary for building research in institutes and universities of their own autonomy in both cognition and targets. 


\section{Acknowledgements}

The authors want to express their thanks for the invitation to attend The Sociology Study. They also want to express their thanks to the reviewer for his valuable comments and corrections of English error in the paper.

\section{References}

Eghbal, M. 2008. "Special Report: Skills Shortage Hinders Asia Pacific Growth.” Euromonitor International, May 6.

Le, H. B., ed. 2007. The Methodology of Scientific Research. Hanoi: Educational Publishing.

Ministry of Education and Training. 2007. University Training Regulations and Colleges Main System Under the Credit System and the Regulation on the Work of Students. Retrieved (http://www. government.vn/portal/page/portal/ government/systemdocument?class_id=1\&_page $=277 \& \mathrm{mo}$ $\mathrm{de}=$ detail\&document_id=38739).

Nguyen, T. D. 2013. "Some Experiences in Building Systems Theoretical Basis of Scientific Research." Presented at Scientific Conference of University Labour and Social Affairs.

Nguyen, T. D. and T. T. Nguyen. 2013. "Opportunities, Challenges and Solutions of ASEAN Print the International Integration Process of Higher Education." Presented at Scientific Conference Higher Education Integration ASEAN: Prospects and Challenges. The University of Foreign Trade.

Vietnam Social Science Institute. 2011. Project of State: Promoting the Combination Researching and Training Between the Institutes and Universities Belong to the Social Science Branch in Vietnam From 2011-2020.

Vietnamese Government. 2004. "Project of Reforming the
Management Structure of the Science and Technology." Issued with Decision no. 171/2004/TTg dated September 28, 2004 by Prime Minister.

Vietnamese Government. 2005a. Decree No. 115/2005/ND-CP Dated September 5, 2005 of the Government on the Regulation Mechanism of Autonomy and Self-responsibility of the Institutions of Science and Technology. Retrieved (http://www.most.gov.vn/Desktop.aspx/VB-decree-115/decr ee-115/F91AECA1E5244542968FC13311E0EE7A/).

_. 2005b. Decree No. 14/2005/NQ-CP Dated November 2, 2005 on the Reformation of Basically and Total Vietnamese Universities Education From 2006-2020. Retrieved (http://moj.gov.vn/vbpq/lists/vn\%20bn\%20php\%20lut/view _detail.aspx?itemid=17258).

. 2007. Decision No. 928/QD-TTg of July 24, 2007 by the Prime Minister on the Project "Social Science Research, Practical Summaries, Building the Scientific Foundation for the Guidelines and Policies of the Party and the State to Promote the Process of Industrialization and Modernization of the Country Under Socialist Orientation”. Retrieved (http://www.government.vn/portal/page/portal/government/ systemdocument?class_id=1\&_page $=80 \&$ mode $=$ detail $\&$ do cument_id=33956).

\section{Bios}

Thi Dung Nguyen, Ph.D., deputy, Department of Inspect, University of Labour and Social Affairs, Hanoi city, Vietnam; research fields: language and literature, education, cultural, social science.

Hong Phuc Nguyen, internal doctor, Military Medical Chamber, National Defense Academy, Hanoi city, Vietnam; research fields: medical examination and treatment, mental, psychological, nerve, social. 